\title{
Comparative Study of Heavy Metals in Dried and Fluid Milk in Peshawar by Atomic Absorption Spectrophotometry
}

\author{
Ghosia Lutfullah, ${ }^{1}$ Abid Ali Khan, ${ }^{2}$ Azra Yasmeen Amjad, ${ }^{1,3}$ and Sajida Perveen ${ }^{4}$ \\ ${ }^{1}$ Centre of Biotechnology \& Microbiology, University of Peshawar, Peshawar 25120, Pakistan \\ ${ }^{2}$ Department of Chemistry, COMSATS Institute of Information Technology, Abbottabad 22060, Pakistan \\ ${ }^{3}$ Department of Nutrition, College of Home Economics, University of Peshawar, Peshawar 25120, Pakistan \\ ${ }^{4}$ Department of Environmental \& Soil Sciences, Agricultural University, Peshawar 25120, Pakistan
}

Correspondence should be addressed to Ghosia Lutfullah; g.lutfullah@gmail.com

Received 21 February 2014; Revised 16 April 2014; Accepted 21 April 2014; Published 20 May 2014

Academic Editor: M. Carmen Yebra-Biurrun

Copyright (C) 2014 Ghosia Lutfullah et al. This is an open access article distributed under the Creative Commons Attribution License, which permits unrestricted use, distribution, and reproduction in any medium, provided the original work is properly cited.

Various essential and toxic heavy metals ( $\mathrm{Ca}, \mathrm{Mg}, \mathrm{Cu}, \mathrm{Zn}, \mathrm{Fe}, \mathrm{Mn}, \mathrm{Pb}, \mathrm{Cd}, \mathrm{Cr}$, and $\mathrm{Ni}$ ) contents in various types of dried (infant formula and powdered) and fluid (fresh and processed) cow milk were assessed by atomic absorption spectrophotometry. The milk samples were collected from local markets of different parts of Peshawar city, Pakistan. Heavy metal concentrations varied significantly depending upon the type of milk. The heavy metal concentrations in most of the samples were within normal and permissible ranges. It was observed that the samples contained considerable amounts of calcium, while magnesium levels were well above the required levels. The results also revealed that copper levels were slightly lower than the permissible limits. The concentration of zinc in dried milk samples was greater than the values for the liquid milk types. Infant milk formulae had higher iron levels as compared to other milk samples because of the added constituents. Significant differences were observed in the mean values of manganese and cadmium in different types of milk. The toxic metals were within the acceptable limits and did not show significant levels leading to toxicity.

\section{Introduction}

Milk is the first food that human encounters which serves as a source of essential nutrients required for the biological functions and growth during early stages of life [1], so commercial infant formulae are designed to mimic the composition of human milk [2]. Formula requiring dilution needs to be measured to correct proportions as the dangers of imbalance exist if excessively concentrated formula or undiluted cow's milk is fed because of preparation error or ignorance [3]. Evaporated and commercially prepared formulae are more expensive than fresh or liquid milk [4]. The infant formulae sometimes lead to nutrient imbalance, poor bioavailability, and hypersensitivity [5]. The bioactive peptides in milk minimize the risk of chronic diseases by boosting immune system [6].
In formula milk, essential elements are added to satisfy nutritional requirements; however, too high additions of certain elements are detrimental, and milk may serve as a vector for the transmission of toxic substances of extrinsic origin [7]. The residues of various antibiotics and antimicrobial drugs may enter milk through medicated feed and improper use of intramuscular drugs. "Essential metals" (Ca, Fe, Zn, $\mathrm{Cu}$, and $\mathrm{Se}$ ) are those required for the complete life cycle of an organism, and absence or insufficiency of which in human diet could induce modifications of metabolic changes and some diseases. However, some essential metals become "toxic" when their concentration is increased, especially the levels exceeding by 40-to-200-fold [8]. If their intakes via food chain cross the permissible levels [9], toxicity may be a problem. The severity of toxic effect depends on nature and concentration of the elements, body resistance, and 
antagonistic effects of other chemical contaminants [10]. The occurrence of elements in foods is a function of the biological roles played by the elements in the structure and physiology of the food issue and adventitious contamination during growth, processing, and preparation. Commercial dried milk and infant formula are deliberately fortified with essential elements such as iron, zinc, and copper to ensure proper nutrients provision [11]. The assessment of heavy metal exposure in the infants' diets is very essential so as to have a clear picture of the intakes, utilization, and retention of essential as well as toxic nutrients.

Multielement surveys have been carried out on trace element concentrations in infant foods, human milk, and powdered infant formula determining mineral elements in the digestion solutions [12]. Concentrations in animals may increase due to environmental contamination [13], resulting in toxic elements in foodstuff [14]. Infants and young children may absorb $50 \%$ of dietary toxic metals as compared with only $10 \%$ by adults [15]. Heavy metals are dangerous because they tend to bioaccumulate in a biological organism faster than being metabolized or excreted [16, 17]. Some metals form stable covalent complexes and interact with macromolecules with affinity for organic binding [18], possessing damaging action at the molecular level. Regulations on milk quality depend upon accurate and precise milk composition [19]. Metals affect the intensity of the Maillard browning reaction in milk. $\mathrm{Fe}^{++}$ions stimulate while $\mathrm{Cu}$ and $\mathrm{Zn}$ suppress browning of the milk mixtures [20,21].

The objectives of the present study were to determine the levels of various essential and toxic trace elements in cow milk from local markets of Peshawar and also to compare their concentration in infant formula/dried milk with fresh/processed liquid cow milk.

\section{Materials and Methods}

A total of forty-six samples from dried, infant formula, fresh, and liquid milk were randomly selected and analyzed in year 2009 for determination of essential and toxic $(\mathrm{Ca}, \mathrm{Mg}$, $\mathrm{Cu}, \mathrm{Zn}, \mathrm{Fe}, \mathrm{Mn}, \mathrm{Pb}, \mathrm{Cd}, \mathrm{Cr}$, and $\mathrm{Ni}$ ) heavy metals. The samples were procured from the local markets of Peshawar. Individual samples of $50 \mathrm{gm}$ of dried and $100 \mathrm{~mL}$ of liquid cow milk were selected in sterile plastic containers and then were labeled, sealed, and stored at suitable cold temperature $\left(0-5^{\circ} \mathrm{C}\right)$. The sample treatment involved digestion, extraction, and preparation of samples before atomic absorption analysis. The $\mathrm{HNO}_{3} / \mathrm{HClO}_{4}$ based wet digestion process was adopted for the identification of trace elements by atomic absorption spectrophotometry as described by AOAC (2000). The temperature-time combinations were optimized for each element, and the accuracy, precision, selectivity, and sensitivity were verified by using Perkin Elmer Double Beam 2380 Atomic Absorption Spectrophotometer with reference sample. The blanks were made in the same way without using any sample. The filtrate was stored in properly labeled and sealed plastic bottles. All the samples were prepared in triplicate.

\section{Statistical Analysis}

The data was analyzed by using Excel data sheets and SPSS computer software version 17 . The simple percentages plus mean values $+\mathrm{SD}$ of the heavy metals were calculated. One-way analysis of variance (ANOVA/LSD) was applied to find out statistical differences among various parameters in different milk samples. The data was also analyzed in terms of Pearson's logarithmic correlation $(<0.05$ and $<0.01)$ to indicate the strength level of the correlation among various heavy metals.

\section{Results}

Milk is a valuable source of essential minerals but some toxic elements may be accidently added during handling, processing, and remixing of milk. The mean concentrations of various essential and toxic heavy metals are presented in Tables 1 and 2 indicating mean values + SD and differences (ANOVA/LSD) among the various categories of milk. Mean values of the mineral elements were closest to the permissible values as determined by international standards [22-24]. The differences in mean values $(\mathrm{Ca}, \mathrm{Mg}, \mathrm{Cu}, \mathrm{Zn}$, and $\mathrm{Fe})$ of the four types of milk were observed to be nonsignificant, whereas there were significant $(P<0.05$ ANOVA/LSD) differences in case of manganese. The mean differences of cadmium were significant in the dried and liquid milk groups, while nonsignificant differences among mean values of lead, chromium, and nickel of the types of milk were observed. The results of the correlation coefficient as presented in Table 3 show the correlations of some minerals with others at different levels of significance.

\section{Discussion}

The concentrations of calcium in all types of milk were of the same order of magnitude as reported in the literature [23], and there were no significant differences in mean values between the two types of each milk group: the powdered milk and the liquid milk. Magnesium being a major mineral required for the regulation of different body processes [10] was found in accordance with the given values [24]. Copper being considered a very important cofactor in the effective utilization of several elements especially iron in body [11] was observed to be slightly lesser than the standards. Zinc as an important constituent in promoting growth and regulation [25] was sufficiently found in most of the samples. Though milk is the poorest source of iron, it performs very important functions in the body, and the calcium in milk itself favors the absorption of dietary iron. It has been observed [26] that low iron status imposes cadmium burden on body, so special attention is required to ensure adequate iron intake to reduce cadmium absorption. The imbalance of iron has been observed to decrease immune functions and to release browning compounds and the oxidized form of sulfur containing amino acids; that is why infant milk formula and some powdered milk samples were found to have added constituents [6]. 
TABLE 1: Concentration of essential mineral elements (ppm) in milk.

\begin{tabular}{|c|c|c|c|c|c|c|c|}
\hline \multirow{2}{*}{\multicolumn{2}{|c|}{ Milk group }} & \multicolumn{6}{|c|}{ Essential minerals } \\
\hline & & Calcium & Magnesium & Copper & Zinc & Iron & Manganese \\
\hline \multicolumn{8}{|c|}{ Total } \\
\hline & Mean + SD & $2106+954$ & $349+205$ & $0.59+0.59$ & $4.79+4.03$ & $1.67+2.08$ & $0.0267+0.02$ \\
\hline & Range & $970-3825$ & $110-875$ & $0.10-2.37$ & $0.09-12.80$ & $0.02-7.54$ & 0.01-0.09 \\
\hline \multicolumn{8}{|c|}{ Infant formula } \\
\hline \multirow{5}{*}{ Dried } & Mean + SD & $3081+277 \mathrm{NS}$ & $540+206 \mathrm{NS}$ & $1.00+0.76 \mathrm{NS}$ & $8.97+2.35 \mathrm{NS}$ & $4.33+2.22 \mathrm{NS}$ & $0.0318+0.02^{*}$ \\
\hline & Range & $2475-3600$ & $250-825$ & $0.11-2.37$ & $4.69-11.34$ & $1.33-7.54$ & $0.01-0.07$ \\
\hline & Powdered & & & & & & \\
\hline & Mean + SD & $3092+502$ NS & $480+173$ NS & $0.90+0.41 \mathrm{NS}$ & $7.31+4.20 \mathrm{NS}$ & $2.42+0.99 \mathrm{NS}$ & $0.0400+0.02^{*}$ \\
\hline & Range & 2075-3825 & $225-875$ & $0.10-1.40$ & $2.22-12.80$ & $1.30-4.30$ & 0.02-0.09 \\
\hline \multirow{6}{*}{ Liquid } & Fresh & & & & & & \\
\hline & Mean + SD & $1333+142$ NS & $240+106 \mathrm{NS}$ & $0.15+0.01 \mathrm{NS}$ & $1.93+1.45 \mathrm{NS}$ & $0.17+0.12 \mathrm{NS}$ & $0.0215+0.01^{*}$ \\
\hline & Range & $1050-1580$ & $120-425$ & $0.12-0.17$ & $0.69-5.01$ & $0.02-0.43$ & $0.01-0.04$ \\
\hline & Processed & & & & & & \\
\hline & Mean + SD & $1228+204$ NS & $185+50 \mathrm{NS}$ & $0.46+0.52 \mathrm{NS}$ & $1.97+1.73 \mathrm{NS}$ & $0.25+0.11 \mathrm{NS}$ & $0.0166+0.01^{*}$ \\
\hline & Range & $970-1725$ & $110-250$ & $0.11-1.70$ & $0.09-4.84$ & $0.06-0.43$ & $0.01-0.03$ \\
\hline
\end{tabular}

*Significant at $P<0.05$ (ANOVA/LSD).

NS: nonsignificant.

TABLE 2: Concentration of toxic mineral elements (ppm) in milk.

\begin{tabular}{|c|c|c|c|c|c|}
\hline \multirow{2}{*}{\multicolumn{2}{|c|}{ Milk group }} & \multicolumn{4}{|c|}{ Toxic mineral elements } \\
\hline & & Lead & Cadmium & Chromium & Nickel \\
\hline \multicolumn{6}{|c|}{ Total } \\
\hline & Mean + SD & $0.0091+0.01$ & $0.1507+0.28$ & $0.0007+0.00$ & $0.0146+0.01$ \\
\hline & Range & $0.0001-0.03$ & 0.01-1.20 & $0.0001-0.003$ & $0.002-0.032$ \\
\hline \multicolumn{6}{|c|}{ Infant formula } \\
\hline \multirow{5}{*}{ Dried } & Mean + SD & $0.0177+0.01 \mathrm{NS}$ & $0.3545+0.40^{*}$ & $0.0015+0.00 \mathrm{NS}$ & $0.0277+0.00 \mathrm{NS}$ \\
\hline & Range & $0.01-0.03$ & 0.09-1.18 & 0.001-0.003 & $0.022-0.032$ \\
\hline & Powdered & & & & \\
\hline & Mean + SD & $0.0170+0.01 \mathrm{NS}$ & $0.2110+0.35^{*}$ & $0.0014+0.00 \mathrm{NS}$ & $0.0202+0.01 \mathrm{NS}$ \\
\hline & Range & $0.01-0.03$ & $0.04-1.20$ & 0.001-0.002 & $0.002-0.032$ \\
\hline \multirow{6}{*}{ Liquid } & Fresh & & & & \\
\hline & Mean + SD & $0.0035+0.01 \mathrm{NS}$ & $0.0408+0.07^{*}$ & $0.0001+0.00 \mathrm{NS}$ & $0.0065+0.00 \mathrm{NS}$ \\
\hline & Range & $0.0001-0.015$ & $0.01-0.25$ & $0.0001-0.0003$ & 0.003-0.009 \\
\hline & Processed & & & & \\
\hline & Mean + SD & $0.0006+0.00 \mathrm{NS}$ & $0.0325+0.02^{*}$ & $0.0001+0.00 \mathrm{NS}$ & $0.0066+0.00 \mathrm{NS}$ \\
\hline & Range & $0.0001-0.0015$ & 0.01-0.09 & $0.0001-0.0003$ & 0.004-0.009 \\
\hline
\end{tabular}

${ }^{*}$ Significant at $P<0.05$ (ANOVA/LSD).

NS: nonsignificant.

Toxic metals are enzyme toxins that disturb the immune mechanism [18], so they need to be eliminated through treatment which can restore the immune system to the maximum effective level. Lead is among the main metals present in the environment which have major toxic effects. Its increased levels have been associated with learning deficiencies in children [2]. There were nonsignificant differences between milk samples. Generally, infant formula reconstituted with tap water is at the highest risk from metal-containing water supply [24]. Deficiency of calcium, iron, and zinc enhances the effects of lead on cognitive and behavioral development. Iron deficiency increases cadmium absorption that affects zinc utilization [27]. Toxic effects of metals may be mediated or enhanced by interaction or deficiency of nutritionally essential metals [20].

The correlation coefficient analysis (Table 3) further verified that calcium was significantly correlated $(<0.05)$ with magnesium. The correlation coefficient analysis explained 
TABLE 3: Correlation coefficients of the mineral elements.

\begin{tabular}{|c|c|c|c|c|c|c|c|c|c|c|c|}
\hline & & $\mathrm{Ca}$ & $\mathrm{Mg}$ & $\mathrm{Cu}$ & $\mathrm{Zn}$ & $\mathrm{Fe}$ & $\mathrm{Mn}$ & $\mathrm{Pb}$ & $\mathrm{Cd}$ & $\mathrm{Cr}$ & $\mathrm{Ni}$ \\
\hline \multirow{2}{*}{$\mathrm{Ca}$} & Pearson's correlation & 1 & $0.684^{* *}$ & $0.502^{* *}$ & $0.732^{* *}$ & $0.729^{* *}$ & $0.466^{* *}$ & $0.767^{* *}$ & $0.373^{*}$ & $0.771^{* *}$ & $0.798^{* *}$ \\
\hline & Sig. (2-tailed) & & 0.000 & 0.000 & 0.000 & 0.000 & 0.001 & 0.000 & 0.011 & 0.000 & 0.000 \\
\hline \multirow{2}{*}{$\mathrm{Mg}$} & Pearson's correlation & $0.684^{* *}$ & 1 & 0.214 & $0.693^{* *}$ & $0.485^{* *}$ & 0.266 & $0.657^{* *}$ & 0.173 & $0.722^{* *}$ & $0.550^{* *}$ \\
\hline & Sig. (2-tailed) & 0.000 & & 0.153 & 0.000 & 0.001 & 0.074 & 0.000 & 0.250 & 0.000 & 0.000 \\
\hline \multirow{2}{*}{$\mathrm{Cu}$} & Pearson's correlation & $0.502^{* *}$ & 0.214 & 1 & $0.423^{* *}$ & $0.521^{* *}$ & $0.547^{* *}$ & $0.469^{* *}$ & 0.194 & $0.512^{* *}$ & $0.460^{* *}$ \\
\hline & Sig. (2-tailed) & 0.000 & 0.153 & & 0.003 & 0.000 & 0.000 & 0.001 & 0.195 & 0.000 & 0.001 \\
\hline \multirow{2}{*}{$\mathrm{Zn}$} & Pearson's correlation & $0.732^{* *}$ & $0.693^{* *}$ & $0.423^{* *}$ & 1 & $0.639^{* *}$ & 0.267 & $0.670^{* *}$ & $0.460^{* *}$ & $0.821^{* *}$ & $0.570^{* *}$ \\
\hline & Sig. (2-tailed) & 0.000 & 0.000 & 0.003 & & 0.000 & 0.073 & 0.000 & 0.001 & 0.000 & 0.000 \\
\hline \multirow{2}{*}{$\mathrm{Fe}$} & Pearson's correlation & $0.729^{* *}$ & $0.485^{* *}$ & $0.521^{* *}$ & $0.639^{* *}$ & 1 & $0.303^{*}$ & $0.480^{* *}$ & $0.492^{* *}$ & $0.681^{* *}$ & $0.730^{* *}$ \\
\hline & Sig. (2-tailed) & 0.000 & 0.001 & 0.000 & 0.000 & & 0.041 & 0.001 & 0.001 & 0.000 & 0.000 \\
\hline \multirow{2}{*}{$\mathrm{Mn}$} & Pearson's correlation & $0.466^{* *}$ & 0.266 & $0.547^{* *}$ & 0.267 & $0.303^{*}$ & 1 & $0.516^{* *}$ & 0.064 & $0.326^{*}$ & $0.378^{* *}$ \\
\hline & Sig. (2-tailed) & 0.001 & 0.074 & 0.000 & 0.073 & 0.041 & & 0.000 & 0.672 & 0.027 & 0.010 \\
\hline \multirow{2}{*}{$\mathrm{Pb}$} & Pearson's correlation & $0.767^{* *}$ & $0.657^{* *}$ & $0.469^{* *}$ & $0.670^{* *}$ & $0.480^{* *}$ & $0.516^{* *}$ & 1 & 0.257 & $0.729^{* *}$ & $0.735^{* *}$ \\
\hline & Sig. (2-tailed) & 0.000 & 0.000 & 0.001 & 0.000 & 0.001 & 0.000 & & 0.085 & 0.000 & 0.000 \\
\hline \multirow{2}{*}{$\mathrm{Cd}$} & Pearson's correlation & $0.373^{*}$ & 0.173 & 0.194 & $0.460^{* *}$ & $0.492^{* *}$ & 0.064 & 0.257 & 1 & $0.488^{* *}$ & $0.433^{* *}$ \\
\hline & Sig. (2-tailed) & 0.011 & 0.250 & 0.195 & 0.001 & 0.001 & 0.672 & 0.085 & & 0.001 & 0.003 \\
\hline \multirow{2}{*}{$\mathrm{Cr}$} & Pearson's correlation & $0.771^{* *}$ & $0.722^{* *}$ & $0.512^{* *}$ & $0.821^{* *}$ & $0.681^{* *}$ & $0.326^{*}$ & $0.729^{* *}$ & $0.488^{* *}$ & 1 & $0.746^{* *}$ \\
\hline & Sig. (2-tailed) & 0.000 & 0.000 & 0.000 & 0.000 & 0.000 & 0.027 & 0.000 & 0.001 & & 0.000 \\
\hline \multirow{2}{*}{$\mathrm{Ni}$} & Pearson's correlation & $0.798^{* *}$ & $0.550^{* *}$ & $0.460^{* *}$ & $0.570^{* *}$ & $0.730^{* *}$ & $0.378^{* *}$ & $0.735^{* *}$ & $0.433^{* *}$ & $0.746^{* *}$ & 1 \\
\hline & Sig. (2-tailed) & 0.000 & 0.000 & 0.001 & 0.000 & 0.000 & 0.010 & 0.000 & 0.003 & 0.000 & \\
\hline
\end{tabular}

** Correlation significant at the 0.01 level.

${ }^{*}$ Correlation significant at the 0.05 level.

that copper was significantly correlated $(<0.05)$ with magnesium and calcium. Manganese was only found to be significantly $(<0.05)$ correlated with cadmium. The correlation analysis summarized the data showing lead as highly correlated $(<0.01)$ with iron and chromium at $<0.05$ significance level. Cadmium was found to be nonsignificantly $(<0.05)$ correlated with other metals. The correlation coefficients stated that chromium was nonsignificantly correlated with all the metals $(<0.05)$. Nickel was found to be only correlated $(<0.05)$ with zinc and chromium.

\section{Conclusion}

The results of the study provide valuable data regarding essential and toxic heavy metals in various powdered and liquid milk samples available in the market. It was observed that the determined values were within the acceptable limits with significant differences in mean values of manganese and cadmium in different types of milk. The milk samples contained considerable amounts of calcium, while magnesium levels were well above the required limits. Copper levels were slightly lower than the permissible allowances. The concentrations of zinc in dried milk samples were up to the mark and better than the liquid types. Infant milk formulae had better iron levels as compared to other milk samples. The correlation coefficients showed that most of the metals were significantly correlated $(>0.05)$ with each other.

\section{Conflict of Interests}

The authors declare that there is no conflict of interests regarding the publication of this paper.

\section{References}

[1] M. Leotsinidis, A. Alexopoulos, and E. Kostopoulou-Farri, "Toxic and essential trace elements in human milk from Greek lactating women: association with dietary habits and other factors," Chemosphere, vol. 61, no. 2, pp. 238-247, 2005.

[2] P. J. Landigran, B. Sonawane, D. Mattison, M. McCally, and A. Gargl, "Chemicalcontaminants in breast milk and their impacts on children's health: an overview," Environmental Health Perspectives, vol. 110, no. 6, pp. A313-A315, 2002.

[3] S. Cancela and M. C. Yebra, "Flow-injection flame atomic absorption spectrometric determination of trace amounts of cadmium in solid and semisolid milk products coupling a continuous ultrasound-assisted extraction system with the online preconcentration on a chelating aminomethylphosphoric acid resin," Journal of the Association of Official Agricultural Chemists, vol. 89, no. 1, pp. 185-191, 2006.

[4] K. K. Hozyasz and A. Ruszczynska, "High manganese levels in milk-based infant formulas," NeuroToxicology, vol. 25, no. 4, p. 733, 2004.

[5] S. Banapurmath, C. R. Banapurmath, and N. Kesaree, "Formula milks: contamination, toxicity and physiological imbalances," Indian Pediatrics, vol. 39, no. 8, pp. 795-797, 2002.

[6] M. L. Pabon and B. Lonnerdal, "Bioavailability of zinc and its binding to casein in milks and formulas," Journal of Trace 
Elements in Medicine and Biology, vol. 14, no. 3, pp. 146-153, 2000.

[7] J. H. Duffus, “heavy metals'-a meaningless term? (IUPAC technical report)," Pure and Applied Chemistry, vol. 74, no. 5, pp. 793-807, 2002.

[8] A. N. Rao, "Trace element estimation: methods and clinical context," Online Journal of Health and Allied Sciences, vol. 4, no. 1, pp. 1-9, 2005.

[9] World Health Organization, 98/5, 1998.

[10] R. Honda, K. Tawara, M. Nishijo, H. Nakagawa, K. Tanebe, and S. Saito, "Cadmium exposure and trace elements in human breast milk," Toxicology, vol. 186, no. 3, pp. 255-259, 2003.

[11] M. A. Khan, "Nutritional adequacy of commercial infant milk formulas," Ecology of Food and Nutrition, vol. 47, no. 2, pp. 188204, 2008.

[12] J. S. LaKind, A. Amina Wilkins, and C. M. Berlin Jr., "Environmental chemicals in human milk: a review of levels, infant exposures and health, and guidance for future research," Toxicology and Applied Pharmacology, vol. 198, no. 2, pp. 184-208, 2004.

[13] E. M. R. Rodríguez, E. D. Uretra, and C. D. Romero, "Concentrations of cadmium and lead in different types of milk," Zeitschrift für Lebensmitteluntersuchung und-Forschung A, vol. 208, no. 3, pp. 162-168, 1999.

[14] E. Coni, B. Bocca, and S. Caroli, "Minor and trace element content of two typical Italian sheep dairy products," Journal of Dairy Research, vol. 66, no. 4, pp. 589-598, 1999.

[15] M. Krachler, T. Prohaska, G. Koellensperger, E. Rossipal, and G. Stingeder, "Concentrations of selected trace elements in human milk and in infant formulas determined by magnetic sector field inductively coupled plasma-mass spectrometry," Biological Trace Element Research, vol. 76, no. 2, pp. 97-112, 2000.

[16] R. Milacic and B. Kralj, "Determination of $\mathrm{Zn}, \mathrm{Cu}, \mathrm{Cd}, \mathrm{Pb}, \mathrm{Ni}$ and $\mathrm{Cr}$ in some Slovenian foodstuffs," European Food Research and Technology, vol. 217, no. 3, pp. 211-214, 2003.

[17] Y. Li, D. F. McCrory, J. M. Powell, H. Saam, and D. JacksonSmith, "A survey of selected heavy metal concentrations in Wisconsin dairy feeds," Journal of Dairy Science, vol. 88, no. 8, pp. 2911-2922, 2005.

[18] A. L. O. Silva, P. R. G. Barrocas, S. D. C. Jacob, and J. C. Moreira, "Dietary intake and health effects of selected toxic elements," Brazilian Journal of Plant Physiology, vol. 17, no. 1, pp. 79-93, 2005.

[19] A. Alimonti, B. Bocca, E. Mannella et al., "Assessment of reference values for selected elements in a healthy urban population," Annali dell'Istituto Superiore di Sanita, vol. 41, no. 2, pp. 181-187, 2005.

[20] J. Contreras-Calderón, E. Guerra-Hernández, and B. GarcíaVillanova, "Utility of some indicators related to the Maillard browning reaction during processing of infant formulas," Food Chemistry, vol. 114, no. 4, pp. 1265-1270, 2009.

[21] S. Birghila, S. Dobrinas, G. Stanciu, and A. Soceanu, "Determination of major and minor elements in milk through ICP-AES," Environmental Engineering and Management Journal, vol. 7, no. 6, pp. 805-808, 2008.

[22] CE (Conformité Européenne), Regulation No. 2001/466, European Union, Official Journal of European Commission.

[23] Codex Alimentarius Commission, World Health Organization, 2007.

[24] Food Standard Agency, "Metals," Foods Surveillance Information Sheet no. 190, Food Standard Agency, London, UK, 1999.

[25] Infant Feeding Action Coalition: INFACT, 03/26A, 2001.
[26] M. E. Soares, M. L. Bastos, and M. Ferreira, "Selective determination of chromium (VI) in powdered milk infant formulas by electrothermal atomization atomic absorption spectrometry after Ion exchange," Journal of the Association of Official Agricultural Chemists, vol. 83, no. 1, pp. 220-223, 2000.

[27] M. Tajkarimi, M. A. Faghih, H. Poursoltani, A. S. Nejad, A. A. Motallebi, and H. Mahdavi, "Lead residue levels in raw milk from different regions of Iran," Food Control, vol. 19, no. 5, pp. 495-498, 2008. 

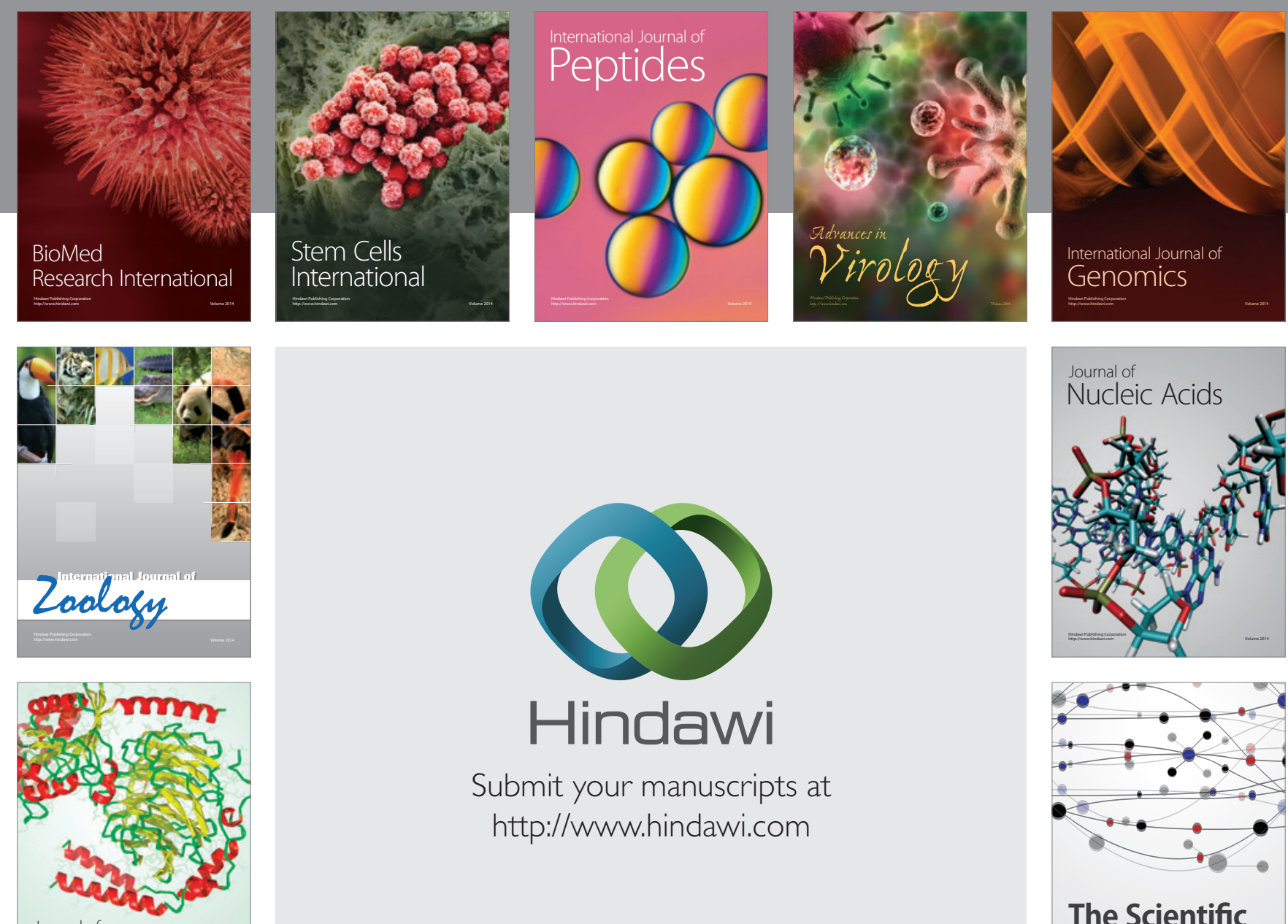

Submit your manuscripts at

http://www.hindawi.com

Journal of
Signal Transduction
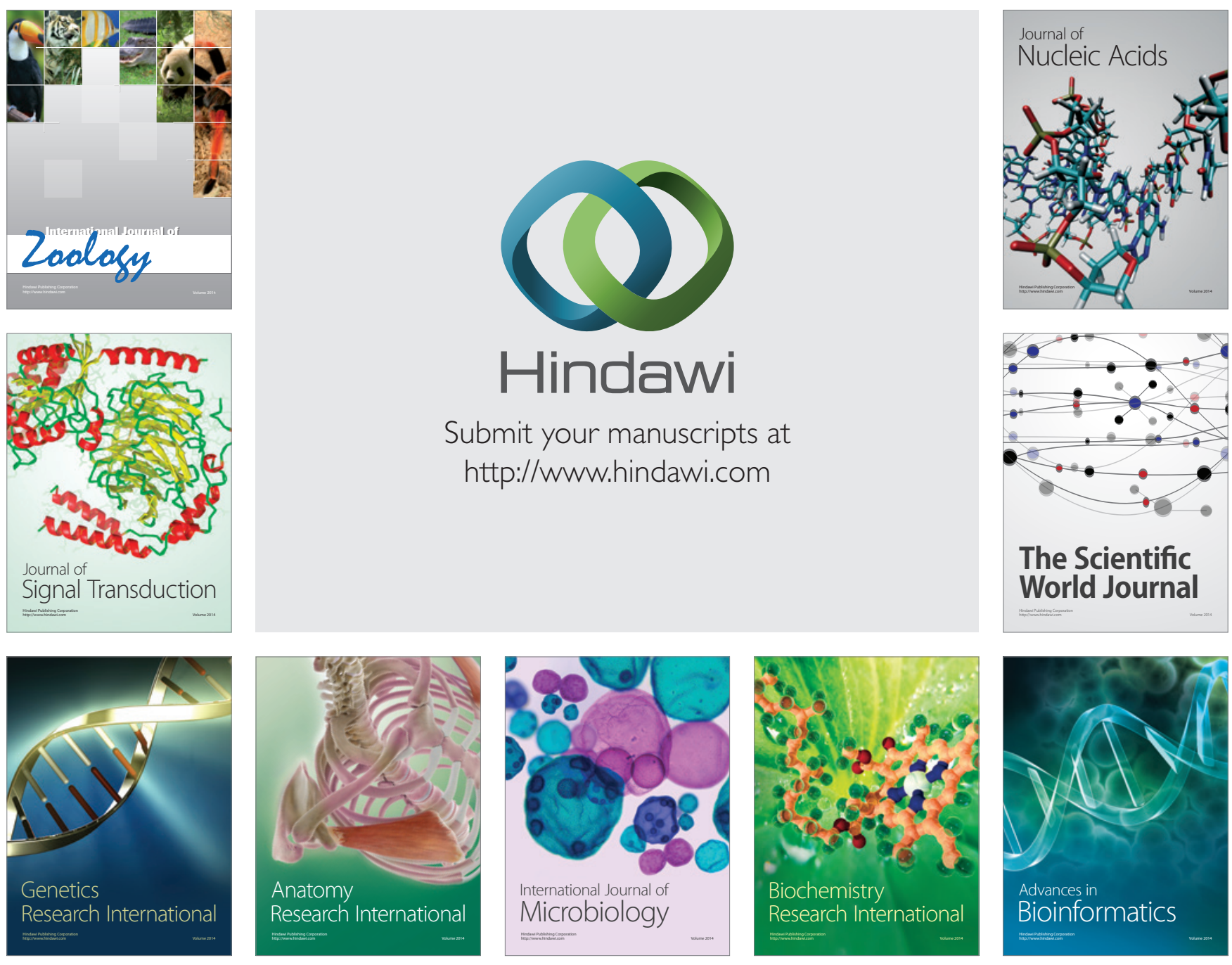

The Scientific World Journal
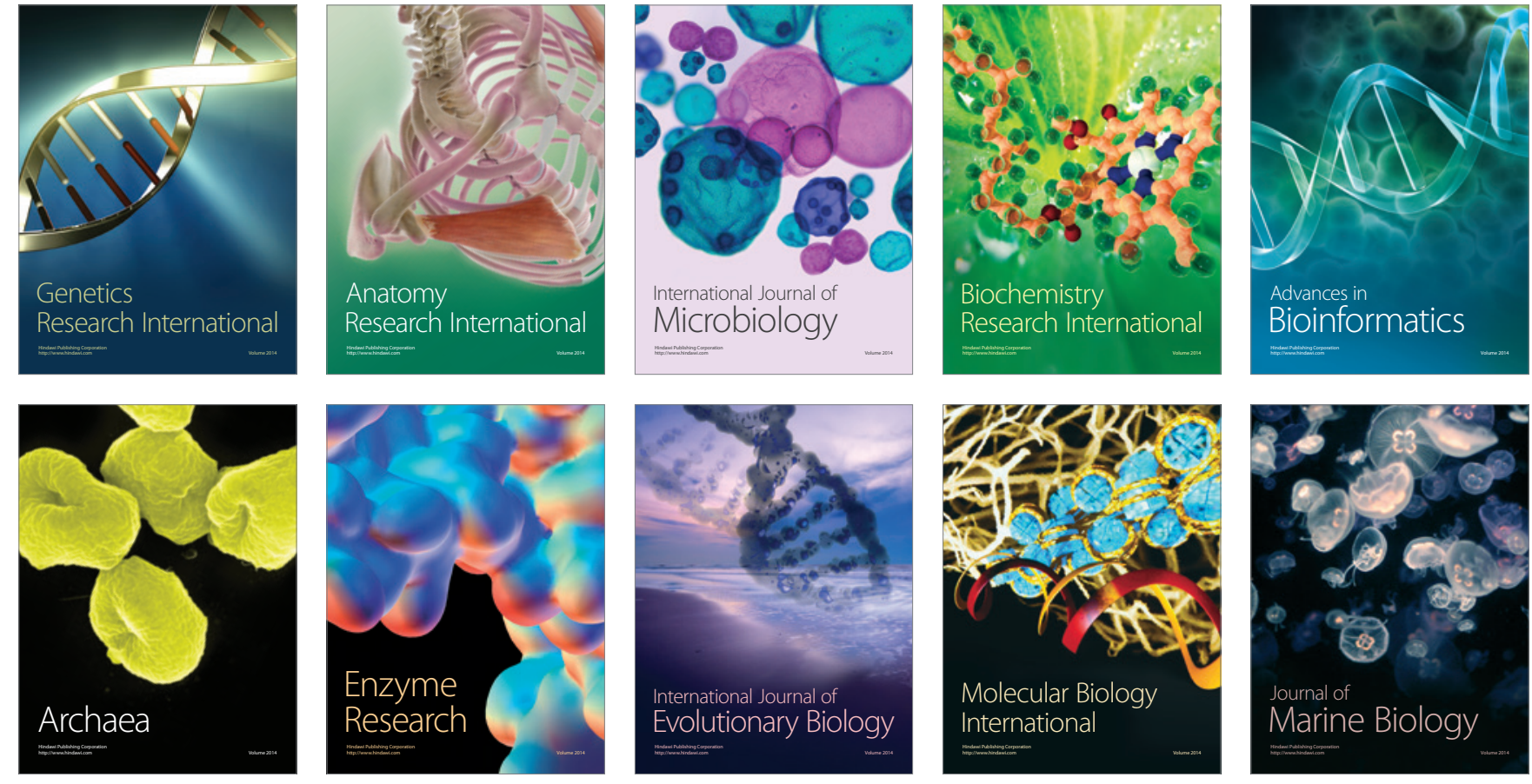